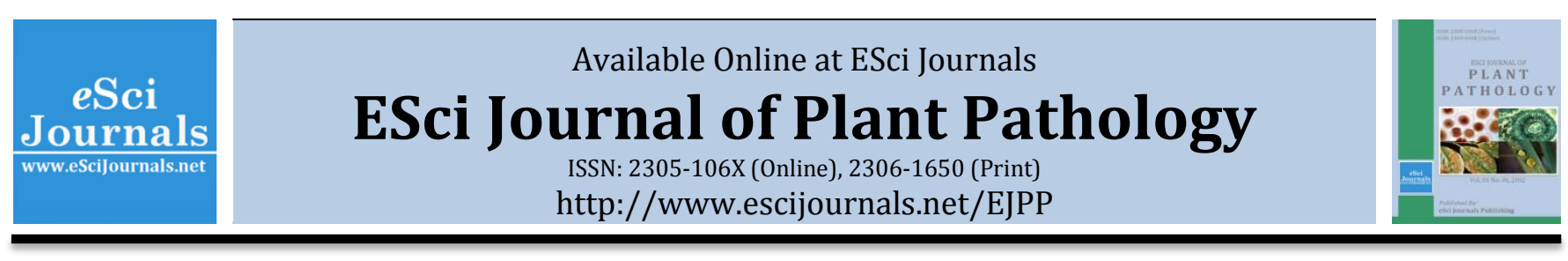

\title{
DEVELOPMENT OF EXPRESSED SEQUENCE TAG-DRIVED SIMPLE SEQUENCE REPEAT MARKERS AND DIVERSITY ANALYSIS OF PHYTOPHTHORA CAPSICI IN CHINA
}

\author{
aLiu Pei-Qing, bWu Min-Liang, a Li Ben-Jin, aLan Cheng-Zhong, aWeng Qi-Yong, bChen Qing-He \\ Institute of Plant Protection, Fujian Academy of Agricultural Sciences, 247 Wusi Road, Fuzhou, Fujian, China. \\ College of Plant Protection, Fujian Agriculture and Forestry University, Fuzhou Fujian, China.
}

\begin{abstract}
A B S T R A C T
Phytophthora capsici is a highly dynamic and destructive pathogen of vegetable and great interests on the genetic structure of $P$. capsici have grown in the world. However, there is little genetic information about $P$. capsici based on the EST-SSR markers. In this study, 193 SSR markers were developed and 33 selected markers were successfully detected and they were polymorphic with the number of alleles per locus ranging from 2 to 7. 4 SSR markers were further selected for genetic diversity analysis and Nei's genetic diversity values of 15 populations ranged from 0.38 to 0.66 , with an average of 0.53 . The higher polymorphism and greater transport ability of these markers among $P$. capsici species were proved by the expected heterozygosity $\left(\mathrm{H}_{\mathrm{e}}=0.64\right)$ and Shannon's index of diversity $(\mathrm{I}=1.14)$, indicating that they maintained a substantial level of genetic diversity. Additionally, the genetic differentiation among the 4 markers $\left(\mathrm{F}_{\mathrm{st}}=0.15\right)$ was moderate and the gene flow among groups was consequent $\left(\mathrm{N}_{\mathrm{m}}=1.69\right)$. Clustering analyses revealed that 15 populations are made of two differentiated genetic clusters and are similar regarding genetic diversity composition. Our results suggest that there are considerable evolutionary potential of $P$. capsici in China and useful management strategies should be adapt to it.
\end{abstract}

Keywords: Phytophthora capsici, expressed sequence tag(EST), simple sequence repeat (SSR), genetic diversity.

\section{INTRODUCTION}

Over the past two decades, numerous types of molecular markers have been employed for studying the population biology and diversity of plant pathogens. Knowledge of the genetic diversity will establish whether populations are genetically differentiated, whether specific genotypes dominate, and what the potential is for developing recombinant populations. These markers have included restriction fragment length polymorphism (RFLP), random amplified polymorphic DNA (RAPD), amplified fragment length polymorphism (AFLP), and inter-simple sequence repeat (ISSR) markers; microsatellites; single nucleotide polymorphisms (SNPs); and mitochondrial haplotype analyses (Martin et al., 2012). Among molecular markers, microsatellites or simple sequence repeat (SSR) markers have become some of the most important

\footnotetext{
* Corresponding Author:

Email: chenqh@faas.cn

(C) 2013 ESci Journals Publishing. All rights reserved.
}

because of advantages such as their relative abundance, co-dominant inheritance, extensive genome coverage, multi-allelic nature, ease of detection by PCR, reproductive ability, and locus specificity ( $\mathrm{Hu}$ et al., 2010). SSRs have been used to investigate the genetic structure and reproductive biology of a wide range of taxonomic groups. They have also been utilized for marker-assisted selection in breeding(Moe et al., 2010), which usually requires a long-term commitment in order to achieve accurate data acquisition from different sources(Lin et al., 2008 and Jiao et al., 2012).

Phytophthora blight caused by Phytophthora capsici (P. capsici) is a serious disease affecting the production of peppers and other important vegetable crops. This blight is soil-borne and initially infects the roots, collars, and lower leaves of plants, potentially causing root rot, leaf and stem blight, and other plant conditions. The propagules produced by $P$. capsici contribute to disease development, while the mycelium initiates disease and produces the zoospores and sporangia required for 
asexual reproduction. To date, the management of $P$. capsici has relied mainly on rotation, sanitation, and fungicide use. Especially, there is no effective method to provide adequate protection against this disease during its infectious period. The genetic structure of pathogen populations reflects their evolutionary history and potential to evolve. Population genetic studies of pathogens are thus useful for the improved management of disease in agricultural ecosystems and may serve as a guide in the cultivation of peppers (McDonald, 1997 and McDonald and Linde, 2002). In the past ten years, molecular genetic markers, such as RAPD, SSR, ISSR and AFLP have been broadly used to learn the genetic structure of Phytophthora species (Yin et al., 2012; Li et al., 2012 and Silvar et al., 2006). However, little EST-SSR markers have been identified and used for genetic studies of $P$. capsici populations (Wang et al., 2009) and these marker also have not been used for the diversity analysis of isolates in China. A major limitation to the wider exploitation of EST-SSR marker is the need for prior species-specific marker isolation, which requires knowledge of the DNA sequence of the SSR flanking regions for which specific primers need to be designed. Such regions are usually conserved within a species, but the likelihood of primers' success between species decreases with an increasing genetic distance. However, the use of second-generation sequencing machines has become increasingly common in EST-SSR marker development. For instance the longer reads produced by the Roche Genome Sequencer using the pyrosequencing method are preferred for this purpose, especially when working with non-model organisms for which comparatively few genomic resources and reference sequences are available (Zhao et al., 2012). Consequently the exploitation of EST-derived SSRs has become increasingly feasible by means of bioinformatic tools such as the SSR identification tool SSRIT (Temnykh et al., 2001) and microsatellite identification tool MISA (Thiel et al., 2003). With the large increase in EST sequences and the application of bioinformatics, a growing number of EST-SSRs have been identified and used extensively for comparative mapping, DNA fingerprinting, and genetic diversity and transferability studies of pathogens (Baldwin et al., 2012). So, there will be more and more EST-SSR can be developed for analysis of the genetic structure of $P$. capsici in China.

Here, we developed 193 EST-SSR markers from the genomic EST resources, and 33 EST-SSR markers were selected to amplify using polymerase chain reaction for detecting 98 P. capsici isolates in China. We showed that 4 polymorphic markers can be selected to assess the genetic diversity and structure of $P$. capsici isolates from different geographical origins in China. Our aim was to obtain population structure information for $P$. capsici in China and to explore the genetic diversity in their populations. Additionally, our results are useful in comparing population parameters of the China populations of the pathogen with other previously described in different regions worldwide.

\section{MATERIALS AND METHODS}

Extraction of DNA: P. capsici isolates samples were collected from a wide geographical distribution in China. The origin, host, mating type, metalaxyl sensitivity, and physiological race are listed in Table S1. All P. capsici samples were cultured in a greenhouse at the Institute of Plant Protection, Fujian Academy of Agricultural Sciences (FAAS), China. Total DNA was extracted from mycelium of each isolate using the cetyltrimethylammonium bromide (CTAB) procedure as described previously (Zhang et al., 2006). The DNA concentrations were evaluated using a NanoDrop 1000 spectrophotometer (Thermo Scientific) and then diluted to $50 \mathrm{ng} / \mathrm{ml}$ and stored at $-20^{\circ} \mathrm{C}$.

SSR identification and primer design: ESTs of $P$. capsici were acquired from the EST database of the National Center for Biotechnology Information (NCBI) (http://www.ncbi.nlm.nih.gov/dbEST/index.html). All the EST sequences were screened for the presence of SSRs using the MISA scripting language (http://pgrc.ipkgatersleben.de/misa/misa.html) to identify microsatellite repeats. We considered only those SSR loci containing perfect repeat units of two to six nucleotides. The minimum SSR length criteria were defined as six reiterations for dinucleotide, and five reiterations for other repeat units. The criteria for SSR scanning was defined as being six repeat units for dinucleotides, five repeat units for tri-nucleotides, and four repeat units for all higher-order repeats. The primers were designed by flanking regions using the software program Primer 3 (http://biotools.umassmed.edu/bioapps/primer3_www. cgi) and were selected to give a PCR product size between 100 and $400 \mathrm{bp}$, using a preferred annealing temperature of approximately $55-65^{\circ} \mathrm{C}$. Primers of $18-$ 22 bases in length and with GC content between 40 and $60 \%$ were synthesized by Sangon Biotech (Shanghai). 
Identification of polymorphic EST-SSR markers: Thirty-three primer pairs were analyzed in gradient PCR amplification based on the DNA template of P. capsici, in order to ascertain the optimal annealing temperature. The PCR reaction volume was $16 \mu \mathrm{L}$ and contained $2 \mu \mathrm{L}$ genomic DNA (100 ng $\left.\mu \mathrm{L}^{-1}\right), 1.5 \mu \mathrm{L} \mathrm{MgCl}_{2}\left(25 \mathrm{mmol} \mathrm{L}^{-1}\right)$, $0.25 \mu \mathrm{L}$ dNTP mixtures $\left(10 \mathrm{mmol} \mathrm{L}^{-1}\right), 2 \mu \mathrm{L} 10 \times$ PCR buffer, $2 \mu \mathrm{L}$ primer $\left(2 \mu \mathrm{mol} \mathrm{L}^{-1}\right), 0.25 \mu \mathrm{L}$ Taq polymerase (10 U $\mathrm{L}^{-1}$ ), and $8 \mu \mathrm{L}$ double-distilled water. The PCR reactions were performed in a TC-512 Gradient PCR cycler (Bio-Rad, USA). A single cycle of $94^{\circ} \mathrm{C}$ for $10 \mathrm{~min}$ was followed by a program of denaturing at $94^{\circ} \mathrm{C}$ for 30 $\mathrm{s}$, and then annealing at temperatures from $47-60^{\circ} \mathrm{C}$ for $30 \mathrm{~s}$, followed by an extension at $72^{\circ} \mathrm{C}$ for $30 \mathrm{~s}$. After 35 cycles, a final extension step was performed at $72^{\circ} \mathrm{C}$ for 5 $\min$.

We conducted PCR analysis of marker polymorphisms, which were processed using the same method and system as the gradient PCR, with the exception that the optimal annealing temperature was adopted. The PCR products were then electrophoresed on a $10 \%$ denaturing polyacrylamide gel electrophoresis (PAGE) and visualized using silver staining. Genotypes showing two, or multiple, loci were scored as homozygous and heterozygous, respectively, and the results were recorded and photographed. Fluoro-fragment analysis was then preformed to confirm the four markers as polymorphic among the 98 P. capsici accessions. Each 20- $\mu \mathrm{L}$ reaction mixture contained $10 \times$ PCR buffer (plus $\mathrm{Mg}^{2+}$ ); $0.8 \mathrm{mM}$ of each dNTP, 1 unit of rTaq polymerase, and 40 ng genomic DNA template; and a total of four primer pairs with 5 pmol of each reverse primer, 4 pmol of each tail primer, and 1 pmol of each forward primer. The PCR products were diluted, mixed with the internal size standard LIZ500 (Applied Biosystems), and loaded on an ABI 3130 Genetic Analyzer. Alleles were scored using GeneMapper version 4.0 software (Applied

Table 1. Results of searches for EST-SSRs.

\begin{tabular}{lc}
\hline Search item & Numbers \\
Total number of sequences examined & 58,277 \\
Total size of sequences examined (kb) & 14691 \\
Total number of SSRs identified & 216 \\
Total number of SSR markers developed & 193 \\
Number of SSR-containing sequences & 209 \\
Number of sequences containing more than 1 SSR & 7 \\
SSRs present in compound formation & 4 \\
\hline
\end{tabular}

Biosystems, Foster City, CA, USA).

Genetic diversity and phylogenetic analysis: The total number of alleles per locus $\left(\mathrm{N}_{\mathrm{a}}\right)$, mean effective number of alleles per population ( $\left.\mathrm{N}_{\mathrm{e}}\right)$, mean observed heterozygosity $\left(\mathrm{H}_{0}\right)$, mean expected heterozygosity $\left(\mathrm{H}_{\mathrm{e}}\right)$, Shannon's information index (I), and Nei's gene diversity (Nei's) were calculated using POPGENE v.1.31. Polymorphism information content (PIC) was calculated by applying the formula given by (Anderson et al., 1993). The population assignments of the species were based on the Bayesian clustering analysis. We also calculated the Wright's F-statistics $\left(\mathrm{F}_{\mathrm{st}}\right)$ to illuminate the genetic differentiation of the populations and estimate the gene flow $\left(\mathrm{N}_{\mathrm{m}}\right)$ among the populations with the equation $\mathrm{N}_{\mathrm{m}}=$ $\left[\left(1 / F_{s t}\right)-1\right] / 4$. NTSYS pc version 2.1 software (Applied Biostatistics, Setauket, NY, USA) (Rohlf, 2002) was used to calculate the Dice genetic similarity coefficient for cluster analysis using the un-weighted pair group method with arithmetic average (UPGMA).

\section{RESULTS}

Frequency distribution of different types of SSR markers: In total, 58,277 ESTs for P. capsici with an average length of 825 bp were downloaded from public databases and subjected to bioinformatic analysis. Of these ESTs, 1155 (about 2\%) contained SSRs. After clustering and assembly, 2954 unique ESTs were identified, including 1483 singletons and 1461 contigs. Among the derived SSRs, the mono-nucleotides were the most abundant repeat, accounting for $91.36 \%$ of total SSRs, followed by di- $(0.98 \%)$, tri- $(7.61 \%)$, and tetra$(0.05 \%)$ nucleotides. Among tri-nucleotides, AGC/CTG was the most abundant, followed by AAG/CTT, and AAT/AAT (Fig. 1).

The proportion of the di-nucleotide repeats was also not evenly distributed, with the two most frequent types (AG/CT and AC/GT) accounting for $0.54 \%$ and $0.41 \%$ of the total motifs, respectively (Table 1 ). 
Analysis for detection of polymorphism in the SSR markers: Furthermore, 33 SSR markers were chosen for locus amplification and polymorphism (Table 2). Amplified DNA fragments were observed and were classified into double and multiple loci generators. In total, 33 markers revealed polymorphism with a mean allelic number of 4.51 and PIC values ranged from 0.13 to 0.79 with an average of 0.59 . The maximum number of SSR alleles was detected by PCSSR24, PCSSR8, PCSSR163, PCSSR3, and PCSSR175, whereas the maximum PIC value (0.79) was observed with SSRPC8.

Table 2. 33 SSR tested for polymorphism with motif and number of repeats. Number of alleles and size range of alleles are given for eight individuals of $P$. capsici.

\begin{tabular}{|c|c|c|c|c|c|c|}
\hline Code & $\begin{array}{l}\text { Repeat } \\
\text { motif }\end{array}$ & Primer sequences $\left(5^{\prime}-3^{\prime}\right)$ & $\begin{array}{l}\text { Annealing } \\
\text { temp }\left({ }^{\circ} \mathrm{C}\right)\end{array}$ & $\begin{array}{l}\text { Expected } \\
\text { size (bp) }\end{array}$ & $\begin{array}{l}\text { No. of } \\
\text { alleles }\end{array}$ & PIC \\
\hline \multirow[t]{2}{*}{ PCSSR178 } & (CTG)6 & TCGCCTCCGTCTTCGGTTTC & 68 & 219 & 4 & 0.59 \\
\hline & & ATCAGGGCCAGCACGAGT & & & & \\
\hline \multirow[t]{2}{*}{ PCSSR158 } & (GAA)7 & AAGATGATTCAACGCGCTCT & 60 & 186 & 2 & 0.25 \\
\hline & & GATGAGTTTCCGTTCCTCCA & & & & \\
\hline \multirow[t]{2}{*}{ PCSSR107 } & (TCT)5 & TGAGCGCCAATTACAACC & 60 & 149 & 5 & 0.38 \\
\hline & & GACGAATGGGAAGGGAAA & & & & \\
\hline \multirow[t]{2}{*}{ PCSSR24 } & (GAG)5 & GAGGCTGATGCCAAGAAA & 58 & 221 & 7 & 0.67 \\
\hline & & AACCAGTCGGCGAAATAC & & & & \\
\hline \multirow[t]{2}{*}{ PCSSR133 } & (TCC) 5 & CAACCAGTCGGCGAAATA & 60 & 174 & 2 & 0.23 \\
\hline & & AACGACGAGGAAGAAGAGC & & & & \\
\hline \multirow[t]{2}{*}{ PCSSR87 } & $(\mathrm{AAG}) 5$ & TAGCAACGGAGTTAGGAGG & 58 & 200 & 5 & 0.39 \\
\hline & & GTTCTTCACGGGATCAGC & & & & \\
\hline \multirow[t]{2}{*}{ PCSSR8 } & (GAA) 5 & ATCAAGACGCAGAACAAGA & 55 & 195 & 7 & 0.79 \\
\hline & & СТTCAACAAGCCAACAAAC & & & & \\
\hline \multirow[t]{2}{*}{ PCSSR117 } & (GGA)5 & GCAACGCGTATAGTCGG & 60 & 220 & 2 & 0.27 \\
\hline & & CTGAAATCGTCTAGCTCCTC & & & & \\
\hline \multirow[t]{2}{*}{ PCSSR176 } & (TCT)5 & GGGTCGCCTAAACAATCT & 60 & 197 & 5 & 0.38 \\
\hline & & AGTAGTATCGTCAAACGCATC & & & & \\
\hline \multirow[t]{2}{*}{ PCSSR177 } & (GAA)6 & GGAGAATGTGGCTGAAGA & 58 & 163 & 6 & 0.59 \\
\hline & & CAGGAAAGCGTATTGGTC & & & & \\
\hline \multirow[t]{2}{*}{ PCSSR182 } & $(\mathrm{GAC}) 6$ & CAGAGTGCCGCCTCCAAT & 65 & 188 & 3 & 0.19 \\
\hline & & CGAACCACCTCGTACTTAGTG & & & & \\
\hline \multirow[t]{2}{*}{ PCSSR74 } & (GCA)6 & TGCTCAACTCGGTGGTG & 65 & 210 & 3 & 0.28 \\
\hline & & CAGGAGACTCAGTCGACGCA & & & & \\
\hline \multirow[t]{2}{*}{ PCSSR113 } & $(\mathrm{GCA}) 5$ & GCAGAGTCTACTACTACCACACG & 65 & 175 & 5 & 0.41 \\
\hline & & AGCTCGTTGCGCCCTACA & & & & \\
\hline \multirow[t]{2}{*}{ PCSSR95 } & $(\mathrm{GCC}) 5$ & CСАТАССТСССАТGCСАТTC & 66 & 224 & 4 & 0.59 \\
\hline & & GGTGCTGTCAGACGCACAA & & & & \\
\hline \multirow[t]{2}{*}{ PCSSR26 } & (GCG)7 & TCGACAAATGCTCCACGACGT & 67 & 211 & 5 & 0.43 \\
\hline & & AACTGCCTGGCGCTGTTG & & & & \\
\hline \multirow[t]{2}{*}{ PCSSR65 } & (GCT)5 & GTAGCGGCGGTTCATAGC & 61 & 221 & 5 & 0.41 \\
\hline & & CATACGGCTATCCGCAGTACC & & & & \\
\hline \multirow[t]{2}{*}{ PCSSR125 } & (GTG)5 & AGGGTCAGACATAGAGGGC & 64 & 195 & 5 & 0.45 \\
\hline & & CCAGTAGGGAAGAGCGTA & & & & \\
\hline
\end{tabular}


ESci J. Plant Pathol. 02 (03) 2013. 137-146

\begin{tabular}{|c|c|c|c|c|c|c|}
\hline PCSSR57 & (GTG)8 & $\begin{array}{l}\text { ACACCGATGCTCTGTTGTCC } \\
\text { ACGACGGGTGCATTGATT }\end{array}$ & 64 & 199 & 3 & 0.35 \\
\hline PCSSR72 & (GTT)5 & $\begin{array}{l}\text { GCCCTGTACGTCAAGGAT } \\
\text { TCTGTTGGGATGGCTACTC }\end{array}$ & 62 & 246 & 3 & 0.43 \\
\hline PCSSR10 & (GT)9 & $\begin{array}{l}\text { TCTCGCCAAAGGAGGAAG } \\
\text { TCGGCAGTAGCAGCATCG }\end{array}$ & 62 & 191 & 2 & 0.24 \\
\hline PCSSR163 & (CT)10 & $\begin{array}{l}\text { AAAGCGCACAGGTCGGAACCA } \\
\text { CCCTGCTGTTTGACTCTGAATACGG }\end{array}$ & 65 & 222 & 7 & 0.65 \\
\hline PCSSR3 & (AG)6 & $\begin{array}{l}\text { GAGAAGCAATAGAAACTGTTGAGGG } \\
\text { CCTCGATACCGAACCAGAAAT }\end{array}$ & 65 & 305 & 7 & 0.58 \\
\hline PCSSR162 & (GT)6 & $\begin{array}{l}\text { ATGCTGATGTGACTTCGCC } \\
\text { GCTCCGCTCCTCACATCTAC }\end{array}$ & 64 & 268 & 5 & 0.38 \\
\hline PCSSR191 & (AAG)6 & $\begin{array}{l}\text { CTGGAGGCAAGAGCAGTAGG } \\
\text { CGGTAGTGAAGAGGCTGAGG }\end{array}$ & 60 & 191 & 4 & 0.58 \\
\hline PCSSR19 & (CCG)5 & $\begin{array}{l}\text { GTCTTCGCTAAAGCCTCCG } \\
\text { AGATGGCCAACAGCGGTTA }\end{array}$ & 63 & 272 & 3 & 0.45 \\
\hline PCSSR127 & $(\mathrm{AGC}) 8$ & $\begin{array}{l}\text { ATAAGGGCCAGCACGAGTC } \\
\text { CTGCCGTCCATCATCTGC }\end{array}$ & 65 & 247 & 2 & 0.12 \\
\hline PCSSR130 & $(\mathrm{AAG}) 7$ & $\begin{array}{l}\text { GCTGTTAAGAAGGCTGAG } \\
\text { ATCATGTTGCTGGAAGAC }\end{array}$ & 60 & 189 & 7 & 0.50 \\
\hline PCSSR151 & $(\mathrm{GA}) 7$ & $\begin{array}{l}\text { AGCGGTTGTCCTCTTGTCG } \\
\text { CTTTCCTTGCTGGGTGGG }\end{array}$ & 64 & 270 & 6 & 0.70 \\
\hline PCSSR187 & (CT)10 & $\begin{array}{l}\text { AACGAGGCAACGTCCATAGT } \\
\text { GCTTAATGCGGCTGAAGAAC }\end{array}$ & 65 & 251 & 4 & 0.54 \\
\hline PCSSR175 & (TC)7 & $\begin{array}{l}\text { TGCTGCGGCTTTCCTTGC } \\
\text { AGCGGTTGTCCTCTTGTCGTTT }\end{array}$ & 64 & 278 & 7 & 0.73 \\
\hline PCSSR54 & (CT)6 & $\begin{array}{l}\text { GCTCCCTCCTCCTCTTCCT } \\
\text { CCGTGGCATCCACCTTGT }\end{array}$ & 64 & 169 & 6 & 0.59 \\
\hline PCSSR93 & (TCG)5 & $\begin{array}{l}\text { GGACGATGACTCCGATGACT } \\
\text { TAGACTTGGTAACCACGGGC }\end{array}$ & 65 & 137 & 5 & 0.70 \\
\hline
\end{tabular}

$\mathrm{N}_{\mathrm{a}}$ : total number of alleles per population; $\mathrm{N}_{\mathrm{e}}$ : mean effective number of alleles per loci; $\mathrm{H}_{\mathrm{o}}$ : mean observed heterozygosity; $\mathrm{H}_{\mathrm{e}}$ : mean expected heterozygosity; I: Shannon's information index, Nei's: expected heterozygosity.

Genetic diversity and differentiation: A total of 164 alleles were amplified with the 4 polymorphic EST-SSR markers in 98 isolates of 15 populations. 80 alleles were amplified in Fujan province and 84 alleles were in the other provinces ( e.g. Beijing, jiangshu) in China. And the number of alleles per locus ranged from 3 to 7 , suggesting high quality of the developed 4 EST-SSR markers. 35 polymorphic alleles were generated among the 164 alleles using the 4 EST-SSR markers. All the genetic information of the 15 populations and 4 EST-SSR markers were listed in Table 3 and Table 4, respectively. Nei's genetic diversity values $\left(\mathrm{H}_{\mathrm{e}}\right)$ of 15 populations ranged from 0.38 to 0.66 , with an average of 0.53 . Values of Shannon's information index (I) per population ranged from 0.52 to 1.20 with an average of 0.85 . The Fjzhouling and Fjfuzhou populations had the highest level of genetic diversity parameters. While the populations Fjlingde and Tianjing possessed the lowest genetic diversity values. The F-statistics results showed moderate genetic differentiation among 15 populations $\left(\mathrm{F}_{\mathrm{st}}=0.15\right)$ and considerable gene flow within populations $\left(\mathrm{N}_{\mathrm{m}}=1.69\right)$, indicating moderate genetic differentiation between 15 populations according to Wright's qualitative guideline, which suggests that Fst values above 0.05 indicate moderate genetic heterogeneity.

Genetic relationship: Based on the POPGENE analysis, the matrices of genetic distances and genetic identities 
between the 15 populations were established and calculated. The genetic distance and genetic identity among the 15 populations were obtained from pairwise comparisons (Table S2). The higher genetic identities were observed between Fjlonghai and Fjfuzhou
(0.9520), Fjfuzhou and Fjmingqing (0.9476), Fjlonghai and Fjxiamen (0.9339). In contrast, the smaller genetic distance were observed between Fjxiamen and Guangdong (0.0307), followed by Fjjianou and Guangdong (0.0314).

Table 3. Results of the genetic analysis of the 15 Phytophthora capsici populations over 4 EST-SSR markers

\begin{tabular}{lcccccc}
\hline & $\mathrm{N}_{\mathrm{a}}$ & $\mathrm{N}_{\mathrm{e}}$ & $\mathrm{H}_{\mathrm{o}}$ & $\mathrm{H}_{\mathrm{e}}$ & $\mathrm{I}$ & Nei's \\
\hline Fjllonghai & 16 & 3.24 & 0.81 & 0.69 & 1.19 & 0.66 \\
Fjxiamen & 12 & 2.50 & 0.92 & 0.63 & 0.94 & 0.57 \\
Fjfuzhou & 18 & 2.66 & 0.86 & 0.63 & 1.12 & 0.61 \\
Fjjianou & 11 & 2.34 & 0.83 & 0.67 & 0.90 & 0.56 \\
FJmingqing & 8 & 1.98 & 0.95 & 0.55 & 0.69 & 0.50 \\
Fjzhouling & 8 & 2.00 & 1.00 & 1.00 & 0.69 & 0.50 \\
Fjlingde & 7 & 1.75 & 0.75 & 0.75 & 0.52 & 0.38 \\
Beijing & 12 & 2.39 & 0.75 & 0.58 & 0.90 & 0.53 \\
Yunnan & 13 & 2.45 & 0.75 & 0.62 & 0.98 & 0.58 \\
Neimeng & 13 & 2.98 & 0.95 & 0.69 & 1.06 & 0.62 \\
Zhejiang & 9 & 1.97 & 0.75 & 0.63 & 0.71 & 0.47 \\
Shandong & 10 & 2.15 & 0.67 & 0.57 & 0.76 & 0.47 \\
Guangdong & 9 & 2.14 & 0.94 & 0.60 & 0.77 & 0.52 \\
Jiangshu & 11 & 2.57 & 0.88 & 0.75 & 0.92 & 0.56 \\
Tianjing & 7 & 1.75 & 0.75 & 0.75 & 0.52 & 0.38 \\
\hline
\end{tabular}

$\mathrm{N}_{\mathrm{a}}$ : total number of alleles per population; $\mathrm{N}_{\mathrm{e}}$ : mean effective number of alleles per loci; $\mathrm{H}_{\mathrm{o}}$ : mean observed heterozygosity; $\mathrm{H}_{\mathrm{e}}$ : mean expected heterozygosity; I: Shannon's information index, Nei's: expected heterozygosity.

Table 4. Results of the genetic analysis of 4 EST-SSR markers over 15 populations.

\begin{tabular}{llllllllll}
\hline ID & $\mathrm{N}_{\mathrm{a}}$ & $\mathrm{N}_{\mathrm{e}}$ & $\mathrm{H}_{\mathrm{o}}$ & $\mathrm{H}_{\mathrm{e}}$ & $\mathrm{F}_{\text {is }}$ & $\mathrm{F}_{\text {it }}$ & $\mathrm{I}$ & $\mathrm{F}_{\text {st }}$ & $\mathrm{N}_{\mathrm{m}}$ \\
\hline PCSSR19 & 3 & 2.02 & 0.89 & 0.51 & -0.88 & -0.71 & 0.73 & 0.09 & 2.49 \\
PCSSR130 & 7 & 2.30 & 0.62 & 0.57 & -0.41 & -0.17 & 1.00 & 0.17 & 1.23 \\
PCSSR151 & 6 & 3.68 & 0.92 & 0.73 & -0.56 & -0.35 & 1.49 & 0.15 & 1.60 \\
PCSSR93 & 5 & 3.63 & 0.93 & 0.73 & -0.53 & -0.26 & 1.36 & 0.18 & 1.46 \\
Mean & 5.25 & 2.91 & 0.84 & 0.64 & -0.60 & -0.37 & 1.14 & 0.15 & 1.69 \\
\hline
\end{tabular}

$\mathrm{N}_{\mathrm{a}}$ : total number of alleles per locus; $\mathrm{N}_{\mathrm{e}}$ : mean effective number of alleles perpopulation; $\mathrm{H}_{\mathrm{o}}$ : mean observed heterozygosity; $\mathrm{H}_{\mathrm{e}}$ : mean expected heterozygosity; $\mathrm{F}_{\mathrm{is}}=\left(\right.$ Mean He - Mean Ho) $/ \mathrm{Mea} \mathrm{n} \mathrm{He} ; \mathrm{N}_{\mathrm{m}}=\left[\left(1 / \mathrm{F}_{\mathrm{ST}}\right)-1\right] / 4$.

The above phenomenon also agreed with $\mathrm{N}_{\mathrm{m}}$ value and the results of cluster analysis. Nei's pairwise genetic distance constructed the consistent UPGMA cluster tree (Fig. 2). The distinction between the 15 populations appeared to be clear for the interspecific difference. In this study, 15 populations were mainly divided into two clades. The one clade was composed of two apparent subgroups, which included the Fjzhouling, shandong and Yunnan populations formed one subgroup, while the Fjlingde population clustered into another subgroup. The other clade was also composed of two apparent subgroups, which included Fjlonghai, Fjxiamen, Fjfuzhou, Fjmingde, Zhejiang, Neimeng, Jiangshu, Beijing and Guangdong populations formed one subgroup, while the Tianjing population clustered into another subgroup. The populations Tianjing and Beijing had a high genetic distance from the other populations and formed an independent branch, respectively.

\section{DISCUSSION}

$P$. capsici is a highly dynamic and destructive pathogen of vegetables in the world, which has been one of the most limiting factors to pepper production. Genetic structure of plant pathogen populations is needed to implement effective control strategies and molecular markers (RAPD, SSR, ISSR and AFLP) have been broadly used to learn the genetic structure of $P$. capsici (Yin et al., 2012; Li et al., 2012 and Silvar et al., 2006). Until now, little is known about the diversity of the pathogen $P$. 
capsici in China, especially based on the EST-SSR markers. Our study was initiated to develop EST-SSR markers from the genomic resources, assess variation in isolates from widely separated locations in China and to gain a baseline understanding of the population structure. We employed the Perl script SSRIT (Kantety et al., 2002) to screen for the presence of SSRs in P. capsici
EST database and our results suggest that about $93 \%$ of SSR markers developed from the 1155 non-redundant ESTs are mono-nucleotides and there only 209 ESTs can be used for development of SSR markers. Especially, the most common tri- repeats in Phytophthora species will be more suitable for SSR marker development (Fig. 1).

Figure 1. Frequency distribution of EST-SSRs based on motif sequence types.

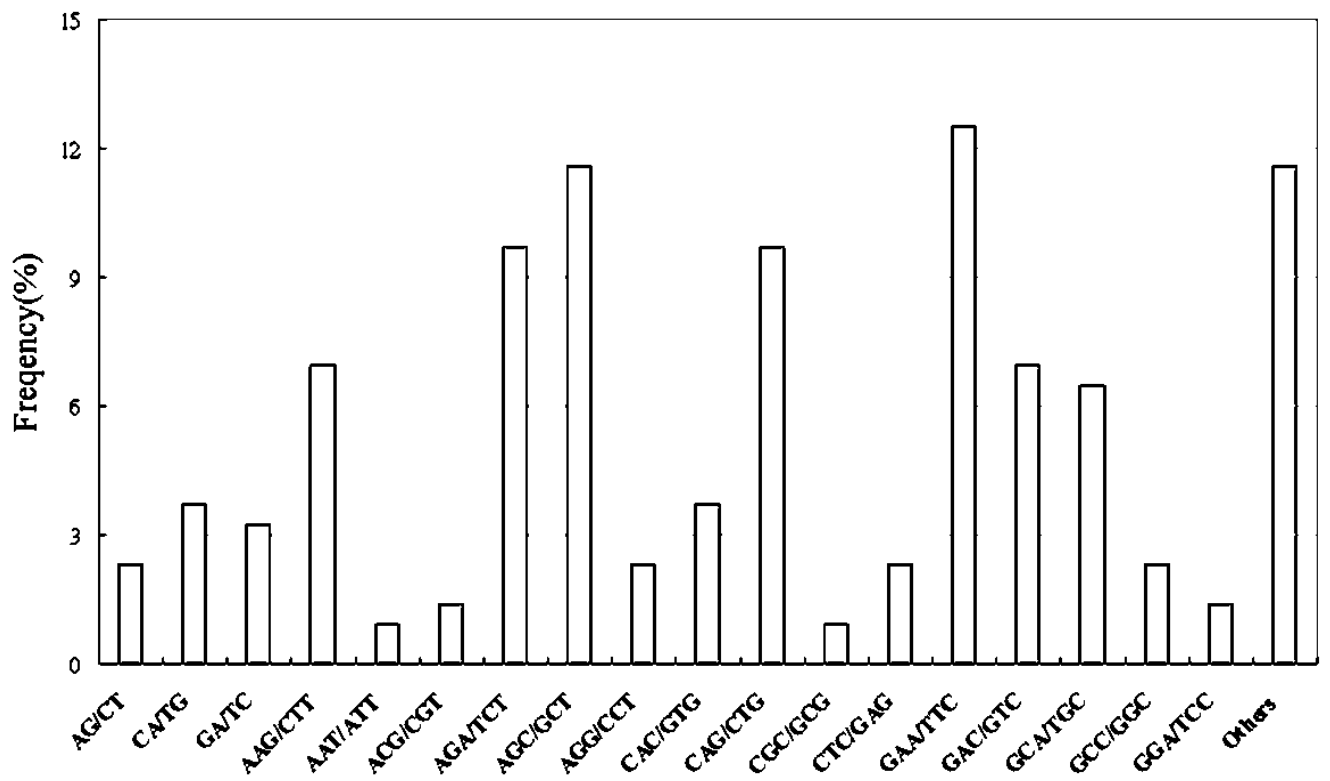

Figure 2. Dendrogram plot for 98 P.capsici isolates based on Fluoro-fragment analysis.

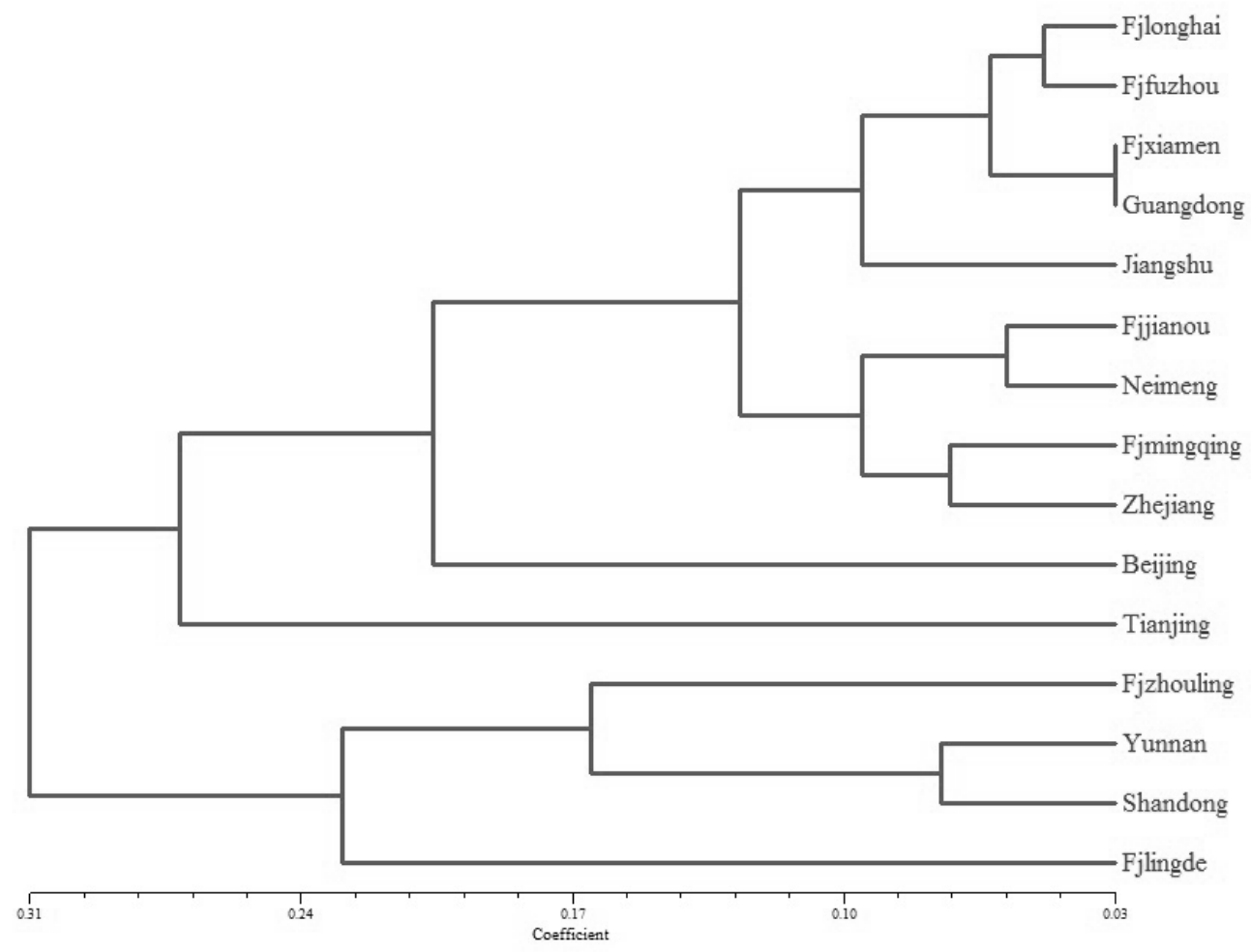


The type and abundance of different motif repeats have been reported to show a variable and uneven distribution in Phytophthora. Earlier reports have indicated that tri- in ESTs are generally the most common motif and that the abundance can be attributed to maintaining an absence of frame shift mutations in the coding regions (Wang et al., 2011). In addition, selection pressure probably eliminates repeats that encode basic amino acids, and tri- repeats correspond to small hydrophilic amino acids are perhaps more easily tolerated. The frequency of SSR motifs here was similar to the frequencies found for the three other Phytophthora EST collections. Meanwhile, the SSR markers in the genome that can be used for P. infestans, $P$. sojae, and P. ramorum were found to be $61.44 \%$, $87.47 \%$, and $88.97 \%$, respectively, indicating that not all the SSRs are located in positions suitable for optimum design.

Previous studies has indicated that 8 out of the 20 RAPD primers tested on $29 \mathrm{P}$. capsici isolates are suitable for further genetic structure investigation (Silvar et al., 2006). As for other AFLP markers, 39-49\% of the AFLP bands were found to be polymorphic, and the estimated heterozygosities ranged from 0.16 to 0.19 within populations in Michigan (Lamour and Hausbeck, 2001). As previously reported, the differences in polymorphisms observed are mainly due to the possible selection against alterations in the conserved sequences and polymorphisms detected by these markers are mainly due to variations in length. Similar findings have been reported for $P$. infestans on potato and tomato in both France and Switzerland (Knapova and Gisi, 2002). Presumably, each of these marker targets has more than one homoeolocus, and these multiple homoeoloci have higher frequencies of deletion of the primer binding site that rejects selection. Spatiotemporal genetic structure of P. capsici with AFLP marker analysis shows that population differentiation in Michigan increased with distance, which indicated that the genetic distances between populations correlated positively with geographical distances and that geographical separation posed an obstacle to the possibility and frequency of genetic exchanges between populations (Lamour and Hausbeck, 2001). The EST-SSR analysis of our study showed that Neimeng population was closely related to those from site Fujian and Zhejiang, which leads to the controversial conclusion that genetic distances and genetic differentiation are negatively associated with geographic distances. In addition, the results of Yunnan and Shandong agreed with the above and the genetic homogenization between the two locations implied a high level of $\mathrm{N}_{\mathrm{m}}$ with each other. Some research has shown that $\mathrm{N}_{\mathrm{m}}$ plays a vital role in genetic differentiation and diversity of species and also has a positive effect on the formation and adaptive evolution of species. The value of $\mathrm{N}_{\mathrm{m}}$ between PCSSR19 and the other PCSSRs was up to 2.49 , showing that genetic exchange was tremendously frequent between these locations. Gene exchange was probably caused by migration of the oomycete along with plant seeds or by transmission of the oospores, which was suitable for explaining the close relationship between isolates separated by a vast geographic distance, since such far dispersal of sporangia seemed unlikely.

SSRs have proven very useful for studying variation among plant pathogens (Delgado et al., 2013). Wright has indicated that the genetic differentiation among populations would be high when the value of $F_{\text {st }}$ was greater than 0.25 . Additionally, as the value of $\mathrm{N}_{\mathrm{m}}$ was less than 1, genetic drift could occur within populations to aggravate genetic differentiation among different populations. Gene flow among locations serves as a powerful evolutionary force to reduce genetic differentiation, and the distinct grouping of isolates based on geographic location is typical for populations that are reproductively isolated (Papetti et al., 2012). Previous studies have indicated that the epidemiology varies according to the geographical location, with populations in South America dominated by clonal reproduction, and populations in the USA and South Africa composed of many unique genotypes in which sexual reproduction is common (Lamour et al., 2012). In our study, great genetic differentiation was revealed among the 15 populations and genetic variations existed among the defined groups. Populations in Tianjing and Beijing have a large genetic distance from the other populations and have formed an independent branch. The other known group was composed of two apparent subgroups: Fjzhouling, Yunnan, and Shandong populations formed one subgroup, while the remaining Fjlingde population clustered into the other subgroup. In general, P. capsici from Fujian, Guangdong, Jiangshu, Neimeng, Zhejiang, Tianjing, Beijing, Yunnan, and Shandong showed strong differences (Table S2 and Fig. 2). Previous studies indicate that outcrossing is an important component of life history and that 
recombination has a significant impact on the genetic structure of populations. The data reported here also support these previous conclusions and outcrossing occurs on a local scale (Table S2 and Fig. 2).

In conclusion, the newly developed $P$. capsici markers developed using the EST-SSR strategy have proven highly informative and useful for studying the diversity and relationship of a set of $P$. capsici individuals in China. These markers represent a significant improvement over the available $P$. capsici genomic resources and this new set of molecular tools and the information derived from their application are essential for $P$. capsici management and breeding research.

\section{ACKNOWLEDGEMENTS}

This work was supported by grants from the Natural Science Foundation for Distinguished Young Scholars of Fujian Province (2011J06010), Doctoral Foundation of FAAS (2012DBS-2), and Special Fund for Agro-scientific Research in the Public Interest (201303018; 200903034).

\section{REFERENCES}

Anderson, J., G. Churchill, J. Autrique, S. Tanksley and M. Sorrells. 1993. Optimizing parental selection for genetic linkage maps. Genome. 36: 181-186.

Baldwin, S., M. Pither-Joyce, K. Wright, L. Chen and J. McCallum. 2012. Development of robust genomic simple sequence repeat markers for estimation of genetic diversity within and among bulb onion (Allium cepa L.) populations. Mol. Breed. 30: 14011411.

Delgado, R., A. Monteros-Altamirano, Y. Li, R. Visser, T. Lee and B. Vosman. 2013. Large subclonal variation in Phytophthora infestans populations associated with Ecuadorian potato landraces. Plant Pathol. 62: 1081-1088.

Hu, J.-b., X.-y. Zhou and J.-w. Li. 2010. Development of novel EST-SSR markers for cucumber (Cucumis sativus) and their transferability to related species. Sci. Hortic. 125: 534-538.

Jiao, Y., H.-m. Jia, X.-w. Li, M.-l. Chai, H.-j. Jia, Z. Chen, G.-y. Wang, C.-y. Chai, E. van de Weg and Z.-s. Gao. 2012. Development of simple sequence repeat (SSR) markers from a genome survey of Chinese bayberry (Myrica rubra). BMC genomics. 13: 201.

Kantety, R. V., M. La Rota, D. E. Matthews and M. E. Sorrells. 2002. Data mining for simple sequence repeats in expressed sequence tags from barley, maize, rice, sorghum and wheat. Plant Mol. Biol. 48: 501-510.

Knapova, G. and U. Gisi. 2002. Phenotypic and genotypic structure of Phytophthora infestans populations on potato and tomato in France and Switzerland. Plant Pathol. 51: 641-653.

Lamour, K. and M. Hausbeck. 2001. Investigating the spatiotemporal genetic structure of Phytophthora capsici in Michigan. Phytopathology. 91: 973-980.

Lamour, K. H., R. Stam, J. Jupe and E. Huitema. 2012. The oomycete broad-host-range pathogen Phytophthora capsici. Mol. Plant Pathol.13: 329337.

Li, P., S. Cao, Y. Dai, X. Li, D. Xu, M. Guo, Y. Pan and Z. Gao. 2012. Genetic diversity of Phytophthora capsici (Pythiaceae) isolates in Anhui Province of China based on ISSR-PCR markers. Genet. Mol. Res. 11: 4285-4296.

Lin, Y., J. Xu, X. Wang, X. Wu, Y. Li and Z. Zhu. 2008. Novel EST-SSR markers for genetic analysis of Phytophthora sojae. Sci. Agric. Sin. 41: 2294-2301.

Martin, F. N., Z. G. Abad, Y. Balci and K. Ivors. 2012. Identification and detection of Phytophthora: reviewing our progress, identifying our needs. Plant Dis. 96: 1080-1103.

McDonald, B. A. 1997. The population genetics of fungi: tools and techniques. Phytopathology. 87: 448453.

McDonald, B. A. and C. Linde. 2002. Pathogen population genetics, evolutionary potential, and durable resistance. Annu. Rev. Phytopathol. 40: 349-379.

Moe, K. T., W. Zhao, H.-S. Song, Y.-H. Kim, J.-W. Chung, Y.I. Cho, P. H. Park, H.-S. Park, S.-C. Chae and Y.-J. Park. 2010. Development of SSR markers to study diversity in the genus Cymbidium. Biochem. Syst. Ecol. 38: 585-594.

Papetti, C., J. M. Pujolar, M. Mezzavilla, M. La Mesa, J. Rock, L. Zane and T. Patarnello. 2012. Population genetic structure and gene flow patterns between populations of the Antarctic icefish Chionodraco rastrospinosus. J. Biogeogr. 39: 1361-1372.

Rohlf, F. J. 2002. NTSYS-pc. Numerical Taxonomy and Multivariate Analysis System, Version 2.1. Exeter Software, New York.

Silvar, C., F. Merino and J. Díaz. 2006. Diversity of Phytophthora capsici in Northwest Spain: analysis of virulence, metalaxyl response, and molecular characterization. Plant Dis. 90: 1135-1142. 
Temnykh, S., G. DeClerck, A. Lukashova, L. Lipovich, S. Cartinhour and S. McCouch. 2001. Computational and experimental analysis of microsatellites in rice (Oryza sativa L.): frequency, length variation, transposon associations, and genetic marker potential. Genome Res. 11: 1441-1452.

Thiel, T., W. Michalek, R. Varshney and A. Graner. 2003. Exploiting EST databases for the development and characterization of gene-derived SSR-markers in barley (Hordeum vulgare L.). Theor. Appl. Genet. 106: 411-422.

Wang, H., P. Huan, X. Lu and B. Liu. 2011. Mining of ESTSSR markers in clam Meretrix meretrix larvae from 454 shotgun transcriptome. Genes Genet. Syst. 86: 197-205.

Wang, Z., D. B. Langston, A. S. Csinos, R. D. Gitaitis, R. R. Walcott and P. Ji. 2009. Development of an improved isolation approach and simple sequence repeat markers to characterize Phytophthora capsici populations in irrigation ponds in southern Georgia. Appl. Environ. Microbiol. 75: 5467-5473.

Yin, J., K. Jackson, B. Candole, A. Csinos, D. Langston and P. Ji. 2012. Aggressiveness and diversity of Phytophthora capsici on vegetable crops in Georgia. Ann. Appl. Biol. 160: 191-200.

Zhang, Z., Y. Li, H. Fan, Y. Wang and X. Zheng. 2006. Molecular detection of Phytophthora capsici in infected plant tissues, soil and water. Plant Pathol. 55: 770-775.

Zhao, Y., C. S. Prakash and G. He. 2012. Characterization and compilation of polymorphic simple sequence repeat (SSR) markers of peanut from public database. BMC Res. notes. 5: 362. 